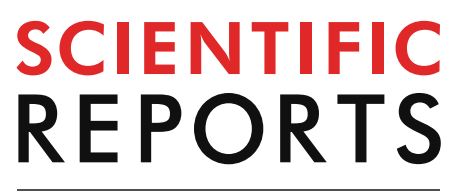

natureresearch

Check for updates

\title{
Influence of temperature
} on the electrochemical window of boron doped diamond: a comparison of commercially available electrodes

\author{
Maeve H. S. McLaughlin ${ }^{1}$, Emma Corcoran ${ }^{2}$, Alexander C. Pakpour-Tabrizi ${ }^{1}$, \\ Débora Campos de Faria² \& Richard B. Jackman ${ }^{1 \bowtie}$
}

This work compares the electrochemical windows of polished and unpolished boron doped diamond (BDD) electrodes with hydrogen and oxygen terminations at a series of temperatures up to $125^{\circ} \mathrm{C}$. The experiment was run at 5 bar pressure to avoid complications due to bubble formation. An alternative method for determining the electrochemical window is compared to the most commonly used method, which defines the window at an arbitrary current density cut-off $\left(J_{\text {cut-off }}\right)$ value. This arbitrary method is heavily influenced by the mass transport of the electrolyte and cannot be used to compare electrodes across literature where different $\mathrm{J}_{\text {cut-off }}$ values have been used. A linear fit method is described which is less affected by the experimental conditions in a given measurement system. This enables a more accurate comparison of the relative electrochemical window from various diamond electrode types from reported results. Through comparison of polished and unpolished BDD electrodes, with hydrogen and oxygen surface terminations, it is determined that the electrochemical window of BDD electrodes narrows as temperature increases; activation energies are reported.

Boron doped diamond (BDD) can act as an exceptional electrode material, with the widest electrochemical window of any known material - that is the potential range that can be applied across a working electrode before the onset of either oxidation or reduction of the electrolyte at its surface ${ }^{1,2}$. To date, there has not been a systematic study reported on how the electrochemical window of BDD is affected by temperature. This has particular relevance to the use of BDD electrodes that are employed in extreme environments, such as oil wells, where the electrode can be exposed to temperatures exceeding $150^{\circ} \mathrm{C}^{3}$. This work aims to give an initial insight into how temperature impacts the electrochemical window of BDD electrodes.

Experimentally, the electrochemical window of an electrode is determined by measuring a polarisation curve over a potential range wide enough to observe the anodic and cathodic decompositions of the electrolyte at the working electrode; the electrochemical window is the region between these two points ${ }^{4}$. There are several methods that can be employed to define the electrochemical window of an electrode from experimental data. The most commonly used method is to plot the current density $(\mathrm{J})$ in $\mathrm{mA} / \mathrm{cm}^{2}$ against the applied potential, then to read off the potential at a defined current density cut off $\left(\mathrm{J}_{\text {cut-off }}\right)$. The arbitrary choice of the $\mathrm{J}_{\text {cut-off }}$ value, reported in the range $0.01-5.0 \mathrm{~mA} / \mathrm{cm}^{2}$, can result in electrochemical windows for the same electrode being quoted to differ by as much as $0.9 \mathrm{~V}^{4-7}$. This method is heavily influenced by mass transport of the electrolyte, meaning that changing the concentration of the electrolyte will affect the electrochemical window recorded ${ }^{4}$. Therefore, it is not possible to accurately compare electrochemical windows that have been determined using different $\mathrm{J}_{\text {cut-off }}$ values. An alternative approach introduced by Olson and Bühlmann has been considered, which was designed to address the inconsistencies that occur when defining the electrochemical window of an electrode by using $J_{\text {cut-off }}$ values $^{8}$. In this method, linear fits are made of the three sections of the CV curve, before and after the oxidation

${ }^{1}$ London Centre for Nanotechnology and Department of Electronic and Electrical Engineering, University College London (UCL), 17-19 Gordon Street, London WC1H 0AH, UK. ' Schlumberger Cambridge Research Ltd. (SCR), Madingley Road, Cambridge CB3 0EL, UK. ${ }^{\boxplus}$ email: r.jackman@ucl.ac.uk 
and reduction of the electrolyte at the working electrode. The intersections of the linear fits are taken to define the electrochemical window ${ }^{4,8}$. The benefit of this technique is that the defined electrochemical window is less sensitive to the concentration of the electrolyte than when the $\mathrm{J}_{\text {cut-off }}$ method is used. Also, this method more closely resembles the method of defining the limits of detection of ion-selective electrodes recommended by IUPAC $^{8,9}$. Here, these methods are compared and contrasted with the aim of setting a standard approach for the determination of electrochemical windows from experimental data. To facilitate investigation of the methods described and to define an electrochemical window from experimental results, heavily boron doped diamond electrodes $\left([\mathrm{B}]>10^{20}\right.$ atoms $/ \mathrm{cm}^{3}$ ) have been used here with two roughnesses: $\mathrm{R}_{\mathrm{A}} \sim 50 \mathrm{~nm}$ and $\mathrm{R}_{\mathrm{A}} \sim 50 \mu \mathrm{m}$, half of which are hydrogen terminated (BDDH) and half of which are oxygen terminated (BDDO). BDDH has been shown to have a slightly narrower electrochemical window than BDDO, however, there are some sensing applications for which BDDH is more suitable $\mathrm{e}^{10,11}$. The $\mathrm{CV}$ measurements are repeated with each electrode over the temperature range $21-125^{\circ} \mathrm{C}$, to identify how the electrochemical window of BDD is affected by temperature. Although $\mathrm{pH}$ will also influence the electrochemical window this is outside the scope of this work. Through use of a buffer system, $\mathrm{pH} 7$, we have fixed the $\mathrm{pH}$ throughout the experiments.

\section{Experimental methods}

Electrochemical grade BDD $\left([\mathrm{B}]>10^{20}\right.$ atoms $\left./ \mathrm{cm}^{3}\right)$ substrates $(10 \times 10 \times 0.5 \mathrm{~mm})$ were purchased from Element Six Ltd. (e6cvd.com). Half of the substrates were unpolished polycrystalline BDD, with surface roughness $\mathrm{R}_{\mathrm{A}} \sim 50 \mu \mathrm{m}$. The remaining substrates were polished polycrystalline BDD (pBDD), with surface roughness $\mathrm{R}_{\mathrm{A}} \sim 50 \mathrm{~nm}$. The substrates were laser cut into $3 \mathrm{~mm}$ diameter pieces at Laser Micromachining Ltd. (lasermicromachining.com). All chemicals, unless otherwise stated, were purchased from Sigma-Aldrich. Milli-pure water, resistivity $18 \mathrm{M} \Omega-\mathrm{cm}$ was used throughout $(0.22 \mu \mathrm{m}$ membrane filter).

BDD surface preparation. Prior to processing, the $3 \mathrm{~mm}$ diameter BDD and pBDD substrates were cleaned with a highly oxidising acid to remove adventitious carbon, hydrocarbons, and graphitic carbon on the surface of the diamonds. During the acid clean, the substrates were heated to $200^{\circ} \mathrm{C}$ for $10 \mathrm{~min}$ in a cleaning solution [ammonium persulfate $(20 \mathrm{~g})$ and concentrated sulfuric acid $(20 \mathrm{~g})$ ] before being placed in the rinsing solution [ammonium hydroxide $(10 \mathrm{ml})$ and hydrogen peroxide $(10 \mathrm{ml})$ ] for $10 \mathrm{~min}^{12}$. The substrates were rinsed thoroughly with water and dried under $\mathrm{N}_{2}$ gas.

The graphitic carbon content at the surface of the electrodes was assessed with a Renishaw micro-Raman spectrometer (532 $\mathrm{nm}$ laser source). The microscope was calibrated using a silicon substrate and the Raman analysis was performed with $20 \times$ magnification, $10 \mathrm{~s}$ exposure and an average was taken over ten accumulations. WiRE (v 2.0) software was used for data acquisition.

One each of the BDD and pBDD substrates were hydrogen terminated in an AX5010 Seki Technotron Inc. reactor with $\mathrm{H}$-plasma for $10 \mathrm{~min}$, at $400{ }^{\circ} \mathrm{C}$ platen temperature (Williamson Dual Wavelength pyrometer), $700 \mathrm{~W}$ power, 35 Torr pressure. One BDD and one pBDD substrate were oxygen terminated via ozone treatment in an Ozone Cleaner NL-UV253, under $10^{-6} \mathrm{mbar}$ vacuum, at ozone generation of $10 \mathrm{~g} / \mathrm{h}$ for one hour. The extent of the hydrogen and oxygen terminations at the substrate surfaces was assessed with contact angle measurements, conducted with a Kruss DSA 1 contact angle goniometer, using $4 \mu$ l water droplets. Kruss DSA1 v1.80 drop shape analysis software was used to determine the contact angle at the three-phase contact point between the water droplet and the electrode surfaces.

Electrode preparations. The $3 \mathrm{~mm}$ diameter BDD pieces were metallised with $\mathrm{Ti}-\mathrm{Pt}-\mathrm{Au}$ and soldered to $\mathrm{Be}-\mathrm{Cu}$ pins to form the working electrode. The electrode construction process involved temperatures sufficient for the formation of the required carbide within the diamond-ohmic contact stack given the duration of the process. The bulkhead into which the electrode was placed was machined from PEEK (polyether ether ketone) in-house. A steel counter electrode ( $4 \mathrm{~mm}$ diameter) and a silver wire reference electrode (1.5 mm diameter) were used. The three electrodes were sealed into the bulkhead body using Loctite Hysol 9483 epoxy (rated to $150{ }^{\circ} \mathrm{C}$ ), which was injected into the channels from behind the pins while applying constant pressure to the front face to avoid leakage of the epoxy to the BDD surface (which would require vigorous polishing to remove, thus destroying the terminations). The bulkhead did require some polishing before the electrochemical measurements to remove dust and other residues left on the electrode surfaces following the sealing of the bulkhead with epoxy. Contact angle measurements were made after the electrodes were polished with $3 \mu \mathrm{m}$ diamond slurry (Kemet International Ltd.) on a PSU-M polishing pad (Kemet International Ltd.) to assess the extent of the hydrogen and oxygen terminations following this polishing procedure. These measurements were made with a Kruss DSA1 contact angle goniometer, using $4 \mu \mathrm{l}$ water droplets, and Kruss DSA1 v1.80 drop shape analysis software was used to determine the contact angle at the three-phase contact point between the water droplet and the electrode surfaces.

Electrochemical measurements. Cyclic voltammetry $(\mathrm{CV})$ measurements, were used to determine the electrochemical window of each BDD working electrode in a $1 \mathrm{M}$ phosphate buffer electrolyte $(0.025 \mathrm{M}$ $\mathrm{K}_{2} \mathrm{HPO}_{4}, 0.025 \mathrm{M} \mathrm{KH}_{2} \mathrm{PO}_{4}, 0.1 \mathrm{M} \mathrm{KCl}$ ) doped with $0.5 \mathrm{mM} \mathrm{3-ferrocenophane} \mathrm{sulfonate} \mathrm{(prepared} \mathrm{in-house}$ at SCR) as a pseudo reference system. Before the CV measurements, the electrodes were polished with a $3 \mu \mathrm{m}$ diamond slurry (Kemet International Ltd.) on a PSU-M polishing pad (Kemet International Ltd.) and rinsed thoroughly with water.

The bulkhead was placed in a PEEK flow cell using Viton o-rings to seal it into place, then the cell was placed in a steel box (to aid heat transfer). A thermocouple was inserted into the bottom of the cell to measure the temperature. The cell was connected to a two-channel syringe pump system (Syrris Asia pump) via Hastelloy 

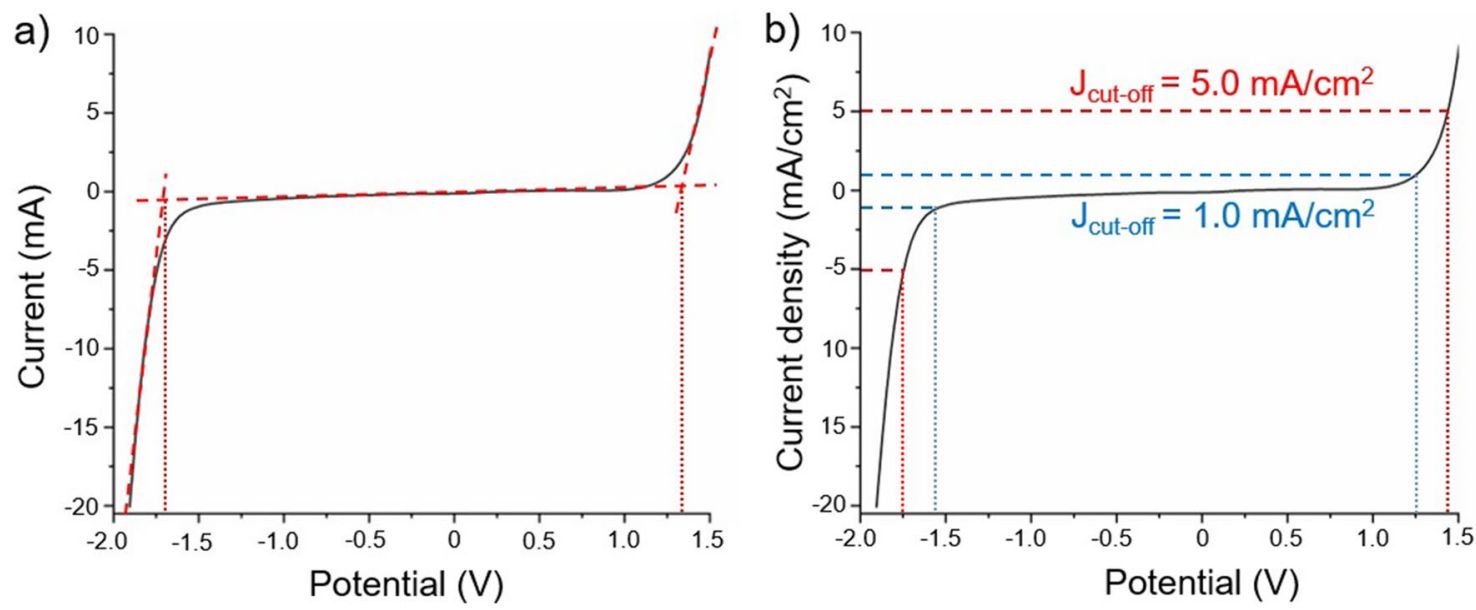

Figure 1. Comparison of the two methods identified for determining the electrochemical window of an electrode from experimental data (BDD working electrode in a $1 \mathrm{M}$ phosphate buffer electrolyte $(0.025 \mathrm{M}$ $\mathrm{K}_{2} \mathrm{HPO}_{4}, 0.025 \mathrm{M} \mathrm{KH}_{2} \mathrm{PO}_{4}, 0.1 \mathrm{M} \mathrm{KCl}$ ) doped with $0.5 \mathrm{mM}$ 3-ferrocenophane sulfonate as a pseudo reference system). The methods are: (a) taking the intersection of the linear fits of the CV curve (the crossing points of the dashed lines $)^{4,9}$ and (b) the well-established $\mathrm{J}_{\text {cut-off }}$ method that determines the electrochemical window by a predefined current density $(\mathrm{J})$ value of 1.0 or $5.0 \mathrm{~mA} / \mathrm{cm}^{2}$.

fittings inside an oven. The flow line to the electrode was held at 5 bar pressure, to prevent the electrolyte from boiling at the elevated temperatures measured. The solution was injected into the cell, via a heating coil inside the oven, to fill the sensing chamber above the electrode (approx. $1 \mathrm{~mm}$ high). Measurements were made after the temperature in the cell was stable for $10 \mathrm{~min}$. The flow was diverted to waste just before measurement, so that static conditions were achieved at the electrode surface whilst taking a scan and reopened after measurement to flush the sensing chamber. CV staircase scans with upper vertex potential $1.5 \mathrm{~V}$, lower vertex potential $-1.9 \mathrm{~V}$ and $0.0085 \mathrm{~V}$ step potential were used to determine the electrochemical windows. The $\mathrm{CV}$ scans were repeated at the scan rates $01,0.5$, and $1 \mathrm{~V} / \mathrm{s}$ for each temperature measured $\left(21,50,75,100\right.$, and $\left.125^{\circ} \mathrm{C}\right)$ with each electrode. As the electrochemical window is independent of the scan rate, the data from each scan rate was combined with the repeats made using each electrode to determine the error in the observed current.

Electrochemical window determination. Two methods for determining the electrochemical window from the experimental data have been explored, as illustrated in Fig. 1, in which the vertical dotted lines represent where the electrochemical window is defined. Figure la shows the current/potential curve obtained experimentally, to which three linear fits have been applied. The electrochemical window is defined as the potential window between the two intersections of the linear fits. Figure $1 \mathrm{~b}$ illustrates the $\mathrm{J}_{\text {cut-off }}$ method for the $\mathrm{J}_{\text {cut-off }}$ values $1.0 \mathrm{~mA} / \mathrm{cm}^{2}$ and $5.0 \mathrm{~mA} / \mathrm{cm}^{2}$. Here the electrochemical window is defined as the potential window between the points where the $\mathrm{J}_{\text {cut-off }}$ value intersects with the current density/potential curve.

\section{Results}

BDD characterisation. The proportion of non-diamond carbon and $\mathrm{sp}^{3}$ diamond carbon on the BDD surfaces was assessed with Raman spectroscopy before and after the acid cleaning process described in "BDD surface preparation" section (Fig. 2).

The extent of the hydrogen and oxygen terminations imparted by the processes described in "BDD surface preparation" section were qualitatively assessed with contact angle measurements. The measurements were repeated after the electrodes were polished with $3 \mu \mathrm{m}$ diamond slurry. These give an insight into the hydrophilic/ hydrophobic nature of the substrate surfaces before and after they were polished (Table 1).

Electrochemical measurements. The CV measurements made with each electrode were repeated four times at each temperature measured $\left(21,50,75,100\right.$, and $\left.125^{\circ} \mathrm{C}\right)$. The average observed current from these repeats with the standard deviation for these values is plotted in Fig. 3.

The activation energy for the oxidation potential for each electrode (Table 2) was determined from the slopes of Arrhenius plots of $\ln$ (current density) against the inverse temperature in Kelvin at the applied potential $-1.4 \mathrm{~V}$ (Fig. 4), which is part way through the oxidative curve for the electrodes at each temperature measured. By plotting the current densities as a function of inverse temperature we can determine the activation energies of the hydrogen evolution reaction with the Arrhenius equation (Eq. 1) where J is the current density, A is the Arrhenius pre-exponential factor, $\mathrm{E}_{\mathrm{A}}$ is the activation energy, $\mathrm{k}_{\mathrm{b}}$ is the Boltzmann constant and $\mathrm{T}$ is the absolute temperature.

$$
J=A \exp \left(\frac{-E_{A}}{k_{b} \cdot T}\right)
$$



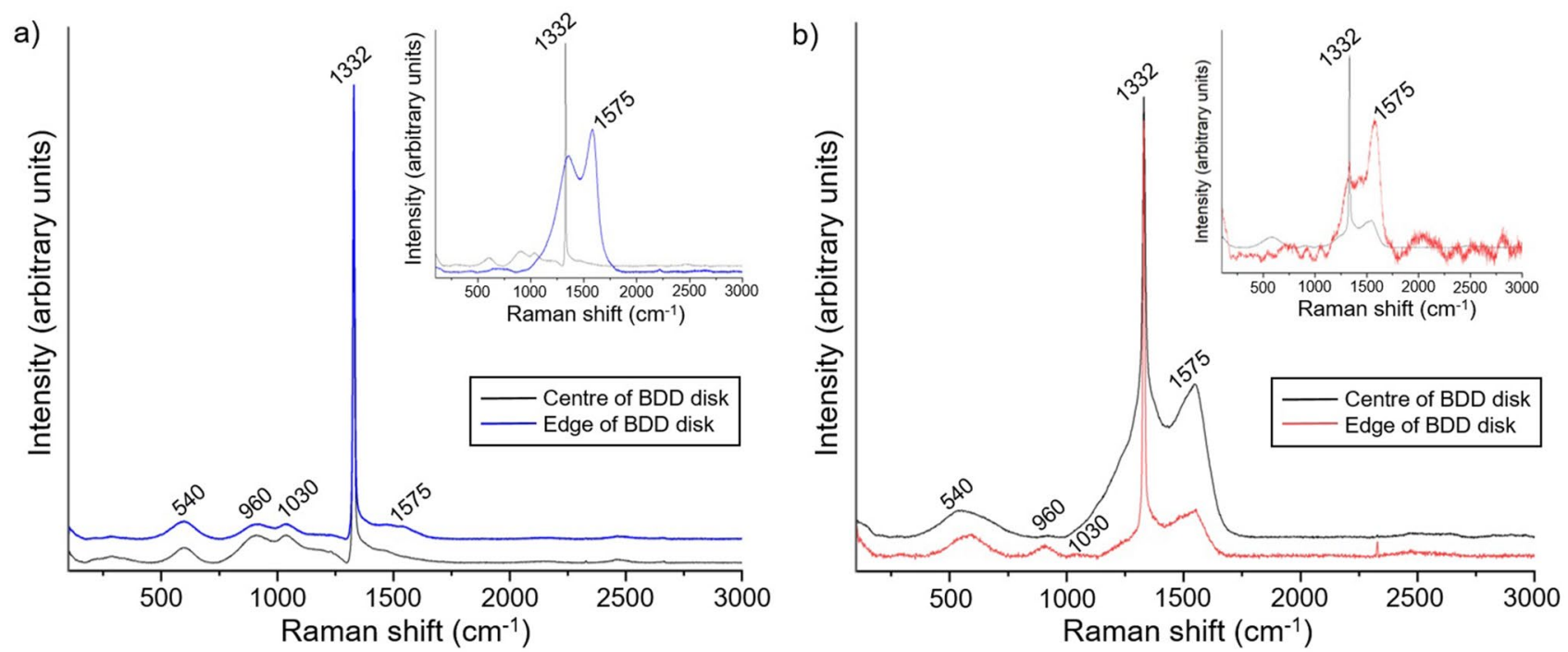

Figure 2. (a) Raman spectrum of unpolished BDD substrate revealing the distinctive $1332 \mathrm{~cm}^{-1}$ peak of the diamond carbon phase, and (inset) Raman spectrum before the substrate was acid cleaned and (b) similar spectrum for the polished $\mathrm{pBDD}$ substrate materials.

\begin{tabular}{|l|l|l|}
\hline \multirow{3}{*}{ Electrode } & After substrate termination & After polishing with $\mathbf{3} \boldsymbol{\mu m}$ diamond slurry \\
\cline { 2 - 3 } & Contact angle $\left(^{\circ}\right)$ & Contact angle $\left(^{\circ}\right)$ \\
\hline Unpolished BDDH & $92 \pm 1.0$ & $78 \pm 1.0$ \\
\hline Polished BDDH & $98 \pm 0.5$ & $55 \pm 1.5$ \\
\hline Unpolished BDDO & $55 \pm 1.0$ & $31 \pm 1.0$ \\
\hline Polished BDDO & $36 \pm 0.5$ & $29 \pm 1.0$ \\
\hline
\end{tabular}

Table 1. Three-phase contact angle on each substrate surface from contact angle measurements with $4 \mu \mathrm{ml}$ water droplets.

Electrochemical window determination. The electrochemical window of each electrode was determined by the two methods described in "Electrochemical window determination" section. A comparison of how the electrochemical windows of the electrodes were affected by temperature with each of these methods is shown in Fig. 5. The electrochemical windows determined with the $\mathrm{J}_{\text {cut-off }}$ method are heavily influenced by the choice of $\mathrm{J}_{\text {cut-off }}$ value. In Fig. 5 this is demonstrated by comparison of the electrochemical windows determined for each electrode with the linear fit method and the $\mathrm{J}_{\text {cut-off }}$ method using the $\mathrm{J}_{\text {cut-off }}$ values $0.5,1.0$, and $5.0 \mathrm{~mA} / \mathrm{cm}^{2}$.

\section{Discussion}

The proportion of non-diamond carbon and $\mathrm{sp}^{3}$ diamond carbon at the BDD surfaces before and after the acid cleaning process was analysed with Raman spectroscopy (Fig. 2). Before the substrates were acid cleaned (inset Fig. 2) the characteristic $1332 \mathrm{~cm}^{-1}$ diamond carbon peak is clearly seen in the centre of the BDD disks. However, at the edge of the disks the $1332 \mathrm{~cm}^{-1}$ peak is broad and has a lower intensity than the non-diamond carbon $\mathrm{G}$ peak at $1575 \mathrm{~cm}^{-1}$. This indicates that when the BDD disks were laser-cut from the $10 \times 10 \mathrm{~cm}^{2}$ squares purchased from Element Six Ltd. non-diamond carbon was most likely sputtered onto the edge of the diamond surface as a result of the laser ablation ${ }^{12}$. The acid cleaning procedure removed a significant proportion of this non-diamond carbon from the BDD surfaces, as indicated by the presence of the characteristic $1332 \mathrm{~cm}^{-1}$ diamond carbon peak at both the centre and edge of each substrate, at a significantly greater intensity than the $1575 \mathrm{~cm}^{-1}$ peak. The shape of the $1332 \mathrm{~cm}^{-1}$ peak after the acid clean is indicative of the crystalline quality of the BDD substrates, as a lower quality diamond that contains more defects would have a shorter phonon lifetime and broader line width than seen in Fig. $2^{1}$.

Comparison of the $1332 \mathrm{~cm}^{-1}$ and $1575 \mathrm{~cm}^{-1}$ peaks can be used to assess the relative proportions of diamond and non-diamond carbon at the substrate surfaces. Although, as the relative intensities of the two peaks are dependent on the grain size, film stress, doping density, and excitation wavelength used, we can only qualitatively compare the two peaks; in the visible region, the sensitivity to $\mathrm{sp}^{2}$ materials is typically 100 times that of $\mathrm{sp}^{313}$. Following the acid clean, the proportion of $\mathrm{sp}^{2}$ carbon at the centre of the substrates is very low when compared to literature values where Raman spectroscopy is supported by other techniques ${ }^{14,15}$. The intensity of the $1575 \mathrm{~cm}^{-1}$ peak remains high in relation to the $1332 \mathrm{~cm}^{-1}$ diamond peak at the edge of the polished BDD substrate, even 

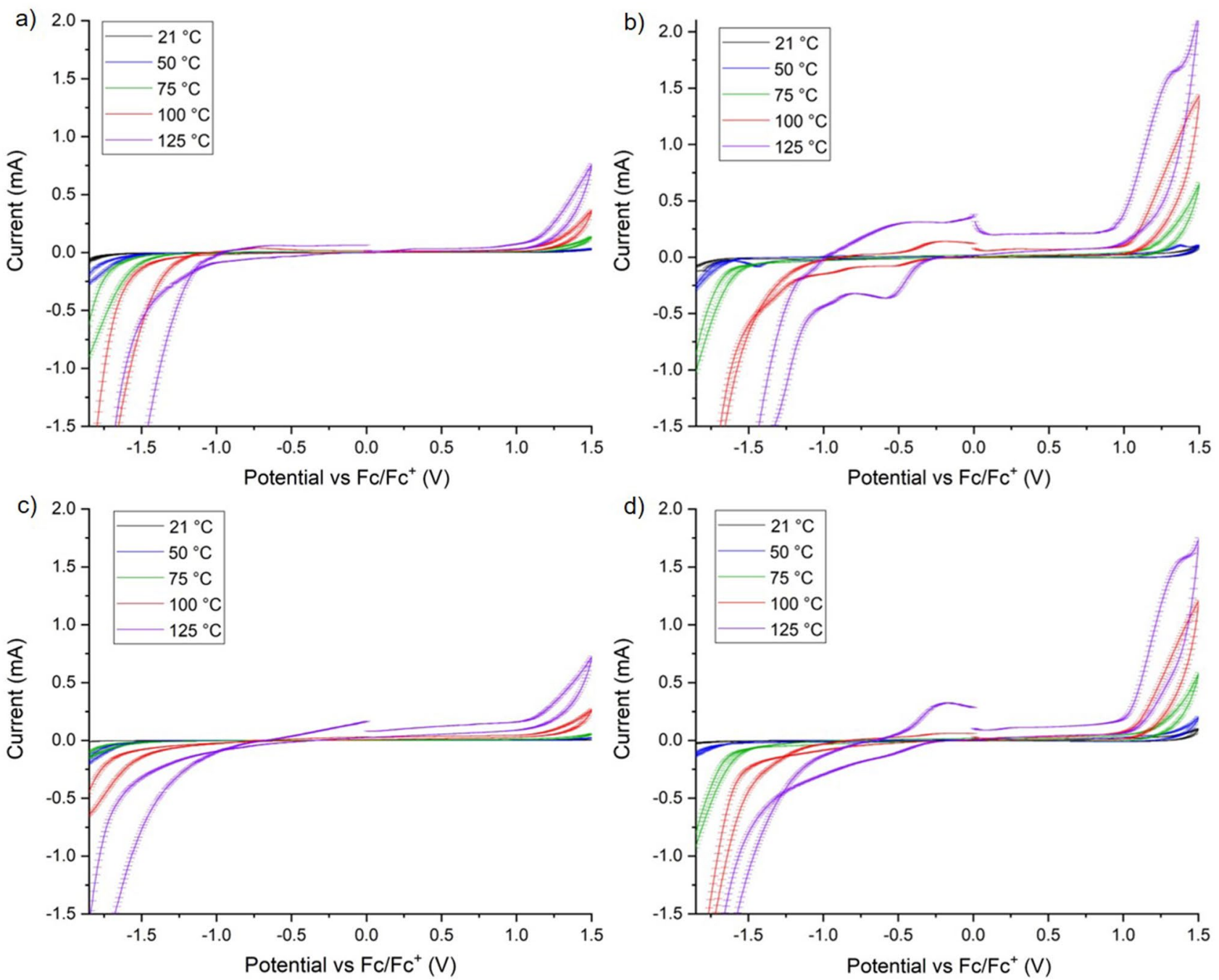

Figure 3. Combined spectra of the $\mathrm{CV}$ average scans and standard deviation across the full temperature range measured for each electrode (a) unpolished BDDH, (b) polished BDDH, (c) unpolished BDDO and (d) polished BDDO at a scan rate of $0.5 \mathrm{~V} / \mathrm{s}$ (similar results obtained at scan rates $0.1 \mathrm{~V} / \mathrm{s}$ and $1.0 \mathrm{~V} / \mathrm{s}$ are in the Supplementary Information).

\begin{tabular}{|l|l|l|}
\hline Electrode & Activation energy (eV) & Error $(\mathrm{eV})$ \\
\hline Unpolished BDDH & $6.68 \times 10^{7}$ & $\pm 0.25 \times 10^{7}$ \\
\hline Polished BDDH & $5.02 \times 10^{7}$ & $\pm 0.68 \times 10^{7}$ \\
\hline Unpolished BDDO & $7.41 \times 10^{7}$ & $\pm 0.23 \times 10^{7}$ \\
\hline Polished BDDO & $5.16 \times 10^{7}$ & $\pm 0.46 \times 10^{7}$ \\
\hline
\end{tabular}

Table 2. Activation energies and standard error for each electrode derived from the Arrhenius plots in Fig. 4.

after the acid clean. This is likely due to the polishing process introducing damage to the diamond surface, which has not been completely removed during the acid clean.

The broad peaks between $500 \mathrm{~cm}^{-1}$ and $1030 \mathrm{~cm}^{-1}$ in the Raman spectra for both the polished and unpolished BDD substrates indicate a high boron doping concentration $\left(>10^{20}\right.$ boron atoms $\left./ \mathrm{cm}^{3}\right)$ within the diamond structures (Fig. 2) ${ }^{16}$. The Fano resonance (asymmetry at the base of the $1332 \mathrm{~cm}^{-1}$ peak) further confirms the high concentration of boron in the diamond lattices, as this relates to the onset of metal-like conductivity in the diamond, which is a result of the boron impurity band transitioning into a continuum state ${ }^{17}$.

The average surface termination across the electrodes was assessed with contact angle measurements (Table 1), after the terminating processes described in "BDD surface preparation" section and again after the electrodes were polished with $3 \mu \mathrm{m}$ diamond slurry, before the CV measurements. Determination of the exact wetting angle from inspection of contact angle measurements is open to error, however, the values for the contact angle 

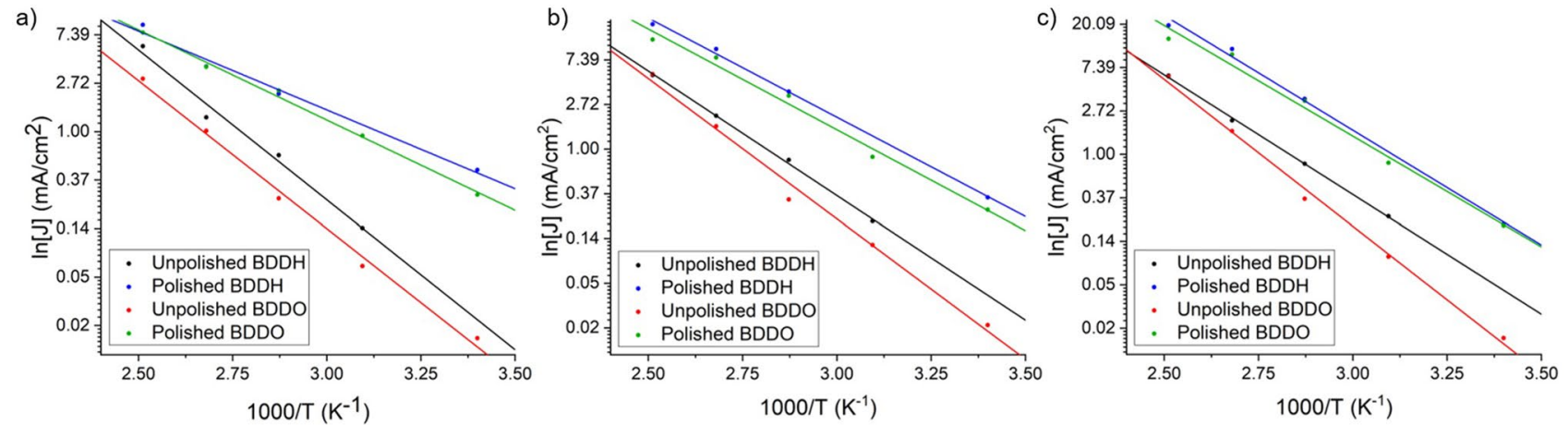

Figure 4. Arrhenius plots of $\ln [\mathrm{J}]$ versus inverse temperature at the potential $-1.4 \mathrm{~V}$, which is part of the way through the electrolyte oxidation at all temperatures from 21 to $125^{\circ} \mathrm{C}$ for each electrode, for each scan rate: (a) $0.1 \mathrm{~V} / \mathrm{s},(\mathbf{b}) 0.5 \mathrm{~V} / \mathrm{s}$ and $(\mathbf{c}) 1.0 \mathrm{~V} / \mathrm{s}$.
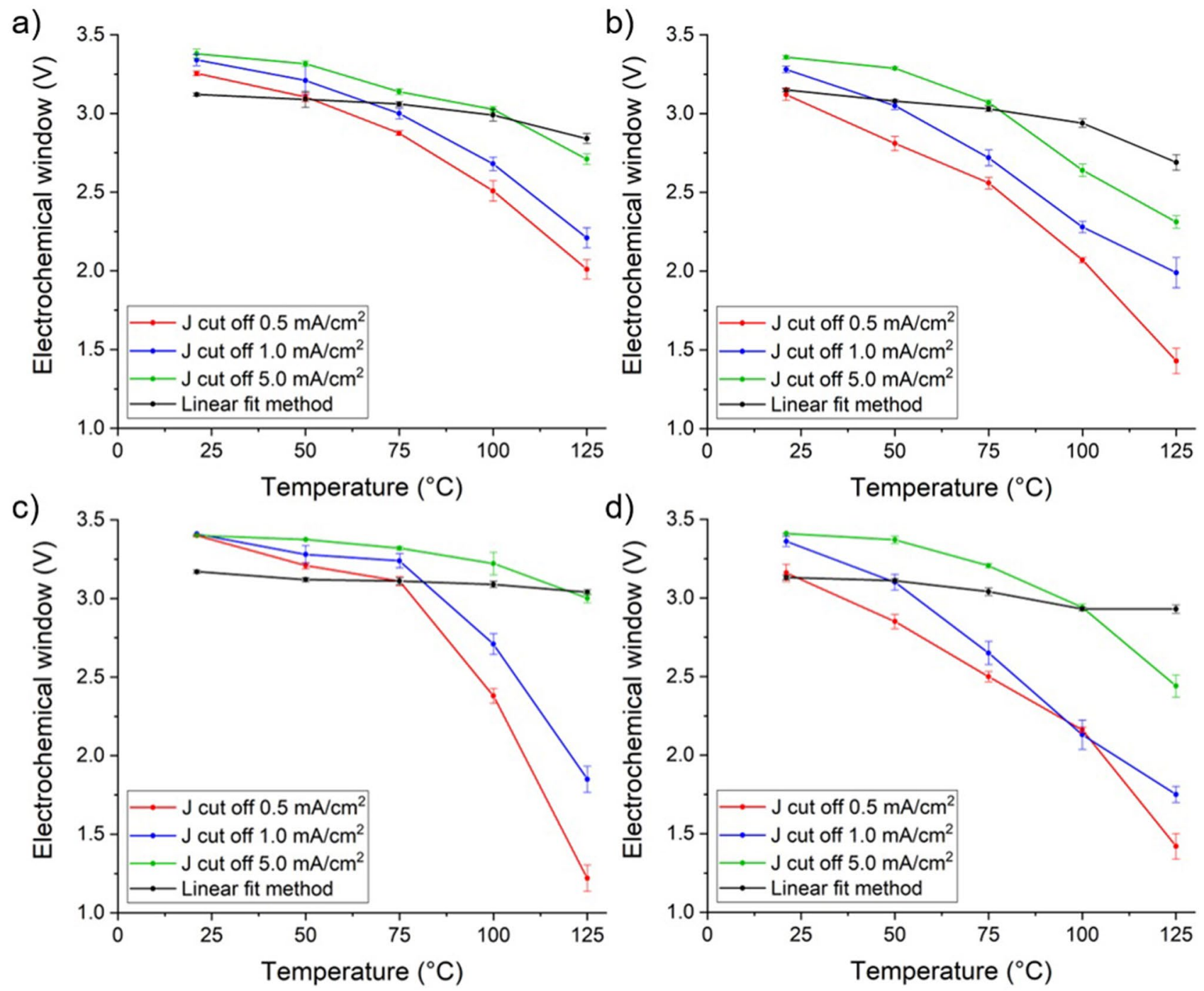

Figure 5. Comparison across the temperature range $21-125^{\circ} \mathrm{C}$ of the electrochemical window of each electrode (a) unpolished BDDH, (b) polished BDDH, (c) unpolished BDDO and (d) polished BDDO, as determined by the $J$ cut off method at $0.5 \mathrm{~mA} / \mathrm{cm}^{2}, 1.0 \mathrm{~mA} / \mathrm{cm}^{2}, 5.0 \mathrm{~mA} / \mathrm{cm}^{2}$ and the intersection of linear fits method described in "Electrochemical window determination" section. 
on the polished and unpolished BDDH electrodes after termination are consistent with a strongly hydrophobic and therefore hydrogen terminated surface, when compared to literature ${ }^{18}$. After polishing with $3 \mu \mathrm{m}$ diamond slurry the contact angles on the unpolished and polished BDDH were reduced to $78^{\circ}$ and $55^{\circ}$ respectively, which corresponds to the hydrogen termination being damaged and the surfaces therefore becoming more hydrophilic. Both sets of contact angles for the unpolished and polished BDDO electrodes are indicative of a hydrophilic and therefore predominantly oxygen terminated surface ${ }^{19}$. The contact angle for a fully oxidised diamond surface would be expected to be $<30^{\circ}$, although, diamond is considered to be predominantly oxygen terminated when the contact angle is between 0 and $60^{1,20}$.

Contact angle measurements are heavily influenced by the environment of the measurement, not just the electrode itself, especially in the case of small electrode sizes. This means that absolute contact angle measurements contain too much error for direct interpretation. However, relative measurements can still be informative. Here, BDDO contact angles were considerably smaller than for $\mathrm{BDDH}$, as expected. The high temperature measurement did not, at least for the duration of the experiments carried out here, lead to any significant change in either. $\mathrm{BDDH}$ with a contact angle of $78^{\circ} \pm 1.0^{\circ}$ after polishing was subsequently measured at $78^{\circ} \pm 2.0^{\circ}$ after the high temperature measurements; $\operatorname{BDDO}\left(31^{\circ} \pm 1.0^{\circ}\right.$ after polishing) was subsequently measured at $30^{\circ} \pm 1.5^{\circ}$.

As the temperature of the $\mathrm{CV}$ measurements was increased from 21 to $125^{\circ} \mathrm{C}$ the onset of oxidation and reduction of the electrolyte at the working BDD electrodes occurred at smaller positive and negative potentials. Therefore, the electrochemical window for each electrode narrowed as the temperature was increased (Fig. 3).

The Arrhenius plots in Fig. 4 show that the current densities of the hydrogen evolution reaction (reduction of the electrolyte) recorded at $-1.4 \mathrm{~V}$ for each electrode are temperature dependent. The anomalous peaks at $-0.5 \mathrm{~V},-0.2 \mathrm{~V}$, and $1.25 \mathrm{~V}$ lead to analogously high current densities for the hydrogen evolution peak at $-1.4 \mathrm{~V}$ for both polished electrodes (BDDH and BDDO), so these points were omitted from the data used to make the Arrhenius plots. The activation energies derived from the Arrhenius plots are shown with the standard error in these values in Table 2. The activation energies are higher and with smaller errors for the unpolished electrodes compared to the polished electrodes, which corresponds to the wider electrochemical windows reported for the unpolished electrodes in Fig. 5, for both methods of determination (with $\mathrm{J}_{\text {cut-off }} 0.1 \mathrm{~mA} / \mathrm{cm}^{2}$ ).

The unpolished electrodes have a lower proportion of $\mathrm{sp}^{2}$ to $\mathrm{sp}^{3}$ carbon at their surface (Fig. 2) than the polished electrodes, meaning that a wider electrochemical window is expected ${ }^{21}$. When the proportion of $\mathrm{sp}^{2}$ carbon is higher, as with the polished electrodes, the oxidation mechanism at the BDD surfaces is affected, leading to changes in the electrocatalytic properties of the electrode surface and reducing the barrier activation to the evolution of hydrogen and reduction of oxygen at the electrode surface, therefore reducing the electrochemical window $^{21,22}$. The activation energies are slightly higher for the BDDO electrodes than the BDDH electrodes (both polished and unpolished), as reported previously ${ }^{10}$. However, the different terminations resulted in significantly smaller changes in the activation energy and electrochemical windows reported than the different surface roughness of the electrodes.

In Fig. 3b,d there are analogous peaks at $-0.5 \mathrm{~V},-0.2 \mathrm{~V}$, and $1.25 \mathrm{~V}$ for the $\mathrm{CV}$ spectra at $125^{\circ} \mathrm{C}$ for both polished electrodes (BDDO and BDDH). As nothing changed in the system other than BDD electrode used, these peaks must be a result of the changes induced by the higher $\mathrm{sp}^{2} / \mathrm{sp}^{3}$ carbon ratio at the surfaces of the polished electrodes ${ }^{21,22}$. In existing literature there are no reports of CV spectra for similar electrodes above $100{ }^{\circ} \mathrm{C}$, so we are unable to make comparisons between this change in the CV spectra and other results. Further investigation is needed.

The linear fit method resulted in electrochemical windows that were apparently narrower at room temperature, than when the $\mathrm{J}_{\text {cut-off }}$ method was used, and less impacted by increasing temperature (Fig. 5). As the temperature of the CV measurements increased and the electrochemical windows narrowed, the linear fits of the curve remained similar. The significant change is that the curves at the beginning of oxidation and reduction of the electrolyte become shallower as the temperature increases (Fig. 6). The change in curvature is more subtle to the linear fit method, meaning that for the same experimental results the electrochemical window will appear to undergo less change with increasing temperature than when the $\mathrm{J}_{\text {cut-off }}$ method is used.

To demonstrate the extent to which the arbitrary choice of the $J_{\text {cut-off }}$ value affects the determined electrochemical window, we compared three $J_{\text {cut-off }}$ values: $0.5,1.0$, and $5.0 \mathrm{~mA} / \mathrm{cm}^{2}$ with the linear fit method (Fig. 5). In Fig. $5 c$ the electrochemical window determined with $\mathrm{J}_{\text {cut-off }} 0.5 \mathrm{~mA} / \mathrm{cm}^{2}$ is $2.31 \mathrm{~V}$, but when determined with $\mathrm{J}_{\text {cut-off }} 5 \mathrm{~mA} / \mathrm{cm}^{2}$ it is $0.88 \mathrm{~V}$ lower, at $1.43 \mathrm{~V}$. This is a significant difference. It is not possible to compare the electrochemical windows quoted across literature where different $J_{\text {cut-off }}$ values have been used and as this method is heavily influenced by the mass transport of the electrolyte it is only accurate to compare electrochemical windows for electrodes that have been determined under the same experimental conditions.

Particularly for the unpolished BDDH and BDDO electrodes (Fig. 5a,c), the linear fit method has a similar trend to the $\mathrm{J}_{\text {cut-off }}$ method using $5.0 \mathrm{~mA} / \mathrm{cm}^{2}$. This highlights the importance of choosing an appropriate $\mathrm{J}_{\text {cut-off }}$ value because it is shown here that the linear fit method is less sensitive to changes in the curvature of the hydrogen evolution or oxygen reduction reactions (Fig. 6), so a less accurate method of determining the electrochemical window. This overshadows the aim of the linear fit method, to determine electrochemical windows by a method that is less influenced by the concentration of the electrolyte than the $\mathrm{J}_{\text {cut-off }}$ method, meaning that comparison between literature is possible ${ }^{4}$.

The electrochemical windows reported in these results were shown to narrow as the temperature of the measurements increased for each of the electrodes. This means that when using these electrodes in high temperature environments the user would need to consider the range of ions that it would be possible to identify, as redox peaks outside the electrochemical window would not be detected. However, each electrode would still be appropriate for use at high temperatures when analysing redox peaks within this range. The unpolished electrodes would offer the most versatility as these electrodes have the widest electrochemical windows, so allow the detection of the widest range of ions. 


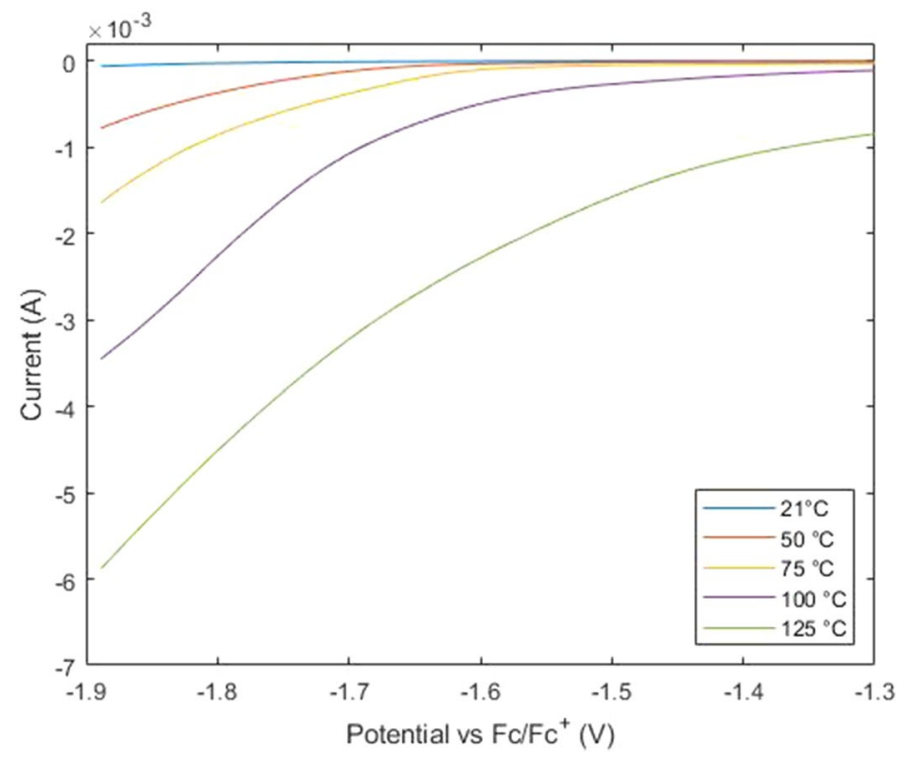

Figure 6. Oxygen reduction reaction at the polished BDDO electrode with increasing temperature from 21 to $125^{\circ} \mathrm{C}$.

\section{Conclusions}

This work has been an investigation into how the electrochemical window of BDD electrodes is affected by temperature and how the method used to determine the electrochemical window from experimental data can affect the apparent result. The experiment was run at 5 bar pressure to avoid complications due to bubble formation. For every electrode, the electrochemical windows became narrower as the temperature increased from 21 to $125^{\circ} \mathrm{C}$, which is to be expected since the redox reaction is thermally activated. The widest electrochemical windows were reported for the unpolished electrodes, which have a lower proportion of $\mathrm{sp}^{2}$ carbon at their surfaces in comparison to the polished electrodes. The influence on the ratio between $\mathrm{sp}^{2}$ and $\mathrm{sp}^{3}$ carbon at the electrode surfaces was shown to have a much more significant impact on the electrochemical window value reported than the hydrogen or oxygen termination of the diamonds.

A reliable standard procedure for determining electrochemical windows has been sought that could be used to make accurate comparisons across the published literature, unlike the commonly used $\mathrm{J}_{\text {cut-off }}$ method. The linear fit method proposed by Olson and Bühlmann is less affected by the assumptions required in the $\mathrm{J}_{\text {cut-off }}$ method; the application of this method to the results reported across the published literature would therefore enable a more accurate comparison of the variation in the value of the electrochemical window due to varying measurement conditions. This is valuable to select one type of electrode versus another. However, it is the electrochemical window determined when using the $\mathrm{J}_{\text {cut-off }}$ method, with a carefully selected $\mathrm{J}_{\text {cut-off }}$ value, that will give the effective electrochemical window that will be relevant for a given experimental arrangement where sensitivity to a given current level is required.

Received: 9 March 2020; Accepted: 9 September 2020

Published online: 24 September 2020

\section{References}

1. Macpherson, J. V. A practical guide to using boron doped diamond in electrochemical research. Phys. Chem. Chem. Phys. 17, 2935-2949 (2015).

2. Svítková, J., Ignat, T., Švorc, L., Labuda, J. \& Barek, J. Diamond sensors for applications to biosensors and biosensing. Crit. Rev. Anal. Chem. 46, 248-256 (2016).

3. Shadravan, A. \& Amani, M. HPHT 101: What every engineer or geoscientist should know about high pressure high temperature wells. Soc. Pet. Eng. J. SPE-163376-MS, 917-943 (2012).

4. Mousavi, M. P. S. et al. Unbiased quantification of the electrochemical stability limits of electrolytes and ionic liquids. J. Electrochem. Soc. 162, A2250-A2258 (2015).

5. O'Mahony, A. M., Silvester, D. S., Aldous, L., Hardacre, C. \& Compton, R. G. Effect of water on the electrochemical window and potential limits of room-temperature ionic liquids. J. Chem. Eng. Data 53, 2884-2891 (2008).

6. Xu, K., Ding, S. P. \& Jow, T. R. Towards reliable values of electrochemical stability limits for electrolytes. J. Electrochem. Soc. 146, 4172-4178 (1999).

7. De Vos, N., Maton, C. \& Stevens, C. V. Electrochemical stability of ionic liquids: General influences and degradation mechanisms. ChemElectroChem 1, 1258-1270 (2014).

8. Olson, E. J. \& Bühlmann, P. Unbiased assessment of electrochemical windows: Minimizing mass transport effects on the evaluation of anodic and cathodic limits. J. Electrochem. Soc. 160, A320-A323 (2013).

9. Lindner, E. \& Umezawa, Y. Performance evaluation criteria for preparation and measurement of macro- and microfabricated ion-selective electrodes (IUPAC technical report). Pure Appl. Chem. 80, 85-104 (2008). 
10. Tryk, D., Tsunozaki, K., Rao, T. N. \& Fujishima, A. Relationship between surface character and electrochemical processes on diamond electrodes: Dual roles of surface termination and near-surface hydrogen. Diam. Relat. Mater. 10, 1804-1809 (2001).

11. McLaughlin, M. H. S., Pakpour-Tabrizi, A. C. \& Jackman, R. B. Diamond electrodes for high sensitivity mercury detection in the aquatic environment: Influence of surface preparation and gold nanoparticle activity. Electroanalysis 31, 1775-1782 (2019).

12. Baral, B., Chan, S. S. M. \& Jackman, R. B. Cleaning thin-film diamond surfaces for device fabrication: An Auger electron spectroscopic study. J. Vac. Sci. Technol. A 14, 2303-2307 (1996).

13. Bormett, R. W. et al. Ultraviolet Raman spectroscopy characterizes chemical vapor deposition during diamond film growth and oxidation. J. Appl. Phys. 77, 5916-5923 (1995).

14. Coffman, F. L. et al. Near-edge X-ray absorption of carbon materials for determining bond hybridization in mixed $\mathrm{sp}^{2} / \mathrm{sp}^{3}$ bonded materials. Appl. Phys. Lett. 69, 568-570 (1996).

15. Huang, L. J. et al. Synchrotron radiation X-ray absorption of ion bombardment induced defects on diamond (100). J. Appl. Phys. 76, 7483-7486 (1994).

16. Prawer, S. \& Nemanich, R. J. Raman spectroscopy of diamond and doped diamond. Philos. Trans. R. Soc. A 362, 2537-2565 (2004).

17. Read, T. L., Bitziou, E., Joseph, M. B. \& Macpherson, J. V. In situ control of local pH using a boron doped diamond ring disk electrode: Optimizing heavy metal (mercury) detection. Anal. Chem. 86, 367-371 (2014).

18. Zielinski, A. et al. Multifrequency nanoscale impedance microscopy (m-NIM): A novel approach towards detection of selective and subtle modifications on the surface of polycrystalline boron-doped diamond electrodes. Ultramicroscopy 199, 34-45 (2019).

19. Mertens, M. et al. Patterned hydrophobic and hydrophilic surfaces of ultra-smooth nanocrystalline diamond layers. Appl. Surf. Sci. 390, 526-530 (2016)

20. Williams, O. A. \& Jackman, R. B. Surface conductivity on hydrogen terminated diamond. Semicond. Sci. Technol. 18, S34-S40 (2003).

21. Einaga, Y., Foord, J. S. \& Swain, G. M. Diamond electrodes diversity and maturity. Mater. Res. Bull. 39, 525-532 (2014).

22. Garcia-Segura, S., Dos Santos, E. V. \& Martínez-Huitle, C. A. Role of $\mathrm{sp}^{3} / \mathrm{sp}^{2}$ ratio on the electrocatalytic properties of boron-doped diamond electrodes: A mini review. Electrochem. Commun. 59, 52-55 (2015).

\section{Acknowledgements}

MHSM thanks the UKs Engineering and Physical Sciences Research Council (EPSRC) and Schlumberger Cambridge Research Ltd. (SCR) for the award of a CASE PhD studentship (EP/N509577/1).

\section{Author contributions}

The work was designed and construed by R.B.J., M.H.S.M., A.P.-T. and D.C.F., and carried out by M.H.S.M. and E.C., under the supervision of R.B.J., A.P.-T. and D.C.F. Data analysis was driven by M.H.S.M., but involved all authors. All authors contributed to the manuscript preparation.

\section{Competing interests}

The authors declare no competing interests.

\section{Additional information}

Supplementary information is available for this paper at https://doi.org/10.1038/s41598-020-72910-x.

Correspondence and requests for materials should be addressed to R.B.J.

Reprints and permissions information is available at www.nature.com/reprints.

Publisher's note Springer Nature remains neutral with regard to jurisdictional claims in published maps and institutional affiliations.

(c) (i) Open Access This article is licensed under a Creative Commons Attribution 4.0 International cc) License, which permits use, sharing, adaptation, distribution and reproduction in any medium or format, as long as you give appropriate credit to the original author(s) and the source, provide a link to the Creative Commons licence, and indicate if changes were made. The images or other third party material in this article are included in the article's Creative Commons licence, unless indicated otherwise in a credit line to the material. If material is not included in the article's Creative Commons licence and your intended use is not permitted by statutory regulation or exceeds the permitted use, you will need to obtain permission directly from the copyright holder. To view a copy of this licence, visit http://creativecommons.org/licenses/by/4.0/.

(C) The Author(s) 2020 